\title{
The Use of KNX/EIB to Control Devices in an Intelligent Home
}

\author{
K. Dzierzek \\ Department of Automatics and Robotics, Faculty of Mechanical Engineering, Bialystok University of Technology, ul. Wiejska 45a, 15-351, \\ Białystok, Poland
}

\section{KEY WORDS}

Intelligent home, intelligent control system.

\begin{abstract}
In the paper made in the Department of Automation and Robotics, intelligent control system implemented in a standard KNX/EIB. Presented is a system and then presents the rules for the design and programming devices. Showing a sample system design, where students will learn the configuration and programming.
\end{abstract}

\section{Introduction}

Continuous development of the civilization of society puts more and more new requirements for utility rooms or buildings. In addition, it is important that these rooms or buildings used by people with disabilities. Until recently it was pointed out that buildings that are used by people with disabilities have special equipment such as: ramps, railings, lifts and wide corridors, respectively. Meanwhile, many areas of banking, hospitals and even residential, is equipped with power circuits, computer, alarm, weather, security and the like. Tasks resulting from their operation are difficult to comprehend, even by people in full working order and what is just for people with disabilities. Hence, many companies in the world use different technical and technological solutions, and at the same range of distinct buildings and equipment.

Buildings equipped with systems performing these tasks is called intelligent because it automatically adapts to the technical characteristics of the object to the requirements of the environment or work with the program.

The project is divided into executive usually thematic projects because of the media, which manages the system. The most important include:

adjust the room temperature - the system must enable, programming of temperatures depending on time of day, while retaining automatic and manual control changes,

adjustment of light intensity - the system controls the light intensity and location of window blinds in the holes,

access control - the system must count the incoming and outgoing person with a specific pass, and also of those people stay in the room,

- installation of alarm - the system in emergencies, smoke, an abnormal increase in temperature, intrusion, alarm system starts,

adjust the room temperature - the system must enable, programming of temperatures depending on time of day, while retaining automatic and manual control changes,

- electrical installation - the system manages the entire electrical system, having regard to safety and saving electricity,

- computer network - the system allows you to use the network to the recipient, ac- 


\section{cording to the schedule.}

In addition, a room or house has a smart device to communicate with you, that is, to inform him of any changes in the room, and gives the ability to change operating parameters. Installation in such homes also have the ability to remotely monitor and change settings.

In recent years, Europe is developing very dynamically intelligent buildings market. The individual housing is most frequently used system for KNX/EIB.

\section{System KNX/EIB}

KNX standard combines three predecessors: BatiBUS, EIB and EHS, they arose in the early ninety. These three formed solutions in Europe for the installation of home and building control initially attempted to gain market yourself. BatiBUS was used in France, Italy and Spain, while the EIB successful in German-speaking countries in northern Europe. EHS dealt with solutions to manufacturers of domestic appliances so. "Brown and white goods."

In 1997, organizations forming systems, the EIB and EHS BatiBUS merged to form an association Konnex (KNX), thus joined efforts in creating a market for smart homes. This organization has set itself the goal of creating a common industry standard that could be proposed as an international standard. The new standard was established in 2002 and was given the name of the KNX. It is based on the EIB and the specification is complemented by new modes, which use the standard BatiBUS and EHS. KNX system is fully compatible with the EIB, however, include more devices beyond the existing capabilities of the standard.

The organization deals with broadcasting Konnex mark KNX, preparation of technical specifications and testing apparatus, assistance in the preparation of national and international standards and develop certification and training rules. Currently, the association has over 100 camera manufacturers system. Businesses with trained personnel are awarded the title KNX/EIB Partner.

$\mathrm{KNX/EIB}$ is a universal system, it allows you to control equipment, small buildings such as apartments or private homes, and office buildings and industrial facilities. For choosing this system suggest: comfort, ease of expansion and rebuilding of the system, safe operation, fault tolerance, as well as saving materials and energy. In literature, the system KNX/EIB is often called the intelligent installation or intelligent technology, the main [1]. $\mathrm{KNX/EIB}$ is a modern system of the XXI century. In Western Europe it is standard in Poland, however, is used only for a few years.

KNX/EIB is an intelligent, decentralized system of implementation of electrical installations, to power, control, signaling, regulation and supervision of electrical equipment and other technical devices and telecommunication [3].

In the system of KNX/EIB traditional switches and sensors and other control devices have been replaced by devices made in digital technology, combined with each other via a single cable running around the entire main building. The big advantage of KNX/EIB is the fact that it flows through the pipe safe low voltage $24 \mathrm{~V}$. Voltage $230 \mathrm{~V}$ is brought solely and directly to the receiver power (lights, electrical sockets). This allows any interior design and installation (eg light switches can be located next to the shower.) Combined Joint various bus systems allow you to create many combinations depending on the user's imagination. You may at any time change the function of various components (eg, a switch does not want to switch on lights overhead, but leave the blinds) without any change in the electrical system. Such an installation has significant advantages over commercial buildings and dwelling houses without clear divisions of space (open space). In place of the control keys can always put the display indicating the status of individual elements (such as an alarm system on, blinds closed, the temperature of $22^{\circ} \mathrm{C}$ ), keyboard lock, motion sensor, a special software for system management, etc. [4].

For devices to be able to communicate among themselves must be properly connected. System KNX/EIB is a distributed system, the main [2] with a topology shown in Figure 1.

System KNX/EIB can be implemented in three standards, due to various transmission media $[4,5$, 6]:

- PowerNet - control occurs through a network 230/400 V. Two different voltage frequencies are used for communication between devices in the system. All system components communicate with each other via the existing network. This type of system has many drawbacks such as highly vulnerable to interference of the electromagnetic field. - RadioBus - control through the radio network. 
The best solution for the management of small installations. Signals between system elements RadioBus are transferred via radio, so there is no control cables. Battery-powered sensors are easily mounted. The disadvantage of such a system is the high cost of equipment.

- INSTABUS - controlled by an electric circuit $24 \mathrm{~V}$ $D C$ powered. This is the voltage (SELV). This type of system is the most common because it had no defects in these systems, KNX/EIB.

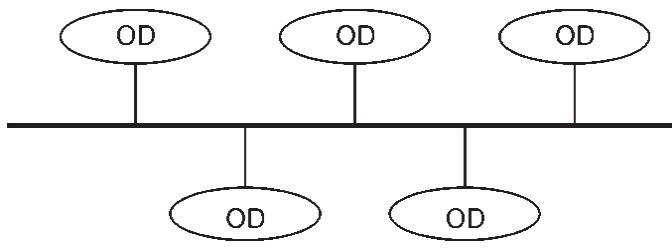

Fig. 1: Figure topology standardised Bus Coupling units; $O D$ - aktors and sensors.

All devices in the system INSTABUS KNX/EIB bus are connected to enable communication between them. It is important that communication takes place without the participation of the control unit. All devices are peers Trunk access to the bus. Decentralization causes that in the event of failure of one device (sensor or an actor), the rest of the elements of the installation is working properly and whatever damaged. The main feature of this system is the separation of the power supply circuit from the bus.

All the sensors and the buttons do not have direct contact with hazardous voltage. This is an important feature of the KNX / ElB because of human safety against electric shock. As the buses used YCYM cable $2 \times 2 \times 0,8$ In practice, it used four dead, and only two: black and red. Two other veins are located in the duct as a reserve that was not to replace the bus, where you will need an additional vein.

Due to the function of the elements of the bus can be divided into actuators and sensors. Sensors measure the values of various physical quantities on the basis of making decisions and send them to actors. Actuators (Implementing Agreements) receive commands and carry them out, they perform the function of the controls receivers (Fig. 2). The basic part of the installation of KNX / EIB is a line. For a single line can be connected up to 64 elements (actuators and sensors). Lines can be combined with each other via so-called areas. linear couplings. In one area, you can connect up to 15 lines. The system can be created by combining 15 areas. In one system can work for 10,000 items. Despite the size of the system, its structure is transparent and logical, since each component has a number of territorial, lines and inside the line. Communication usually takes place within a single line. Linear couplings prevent the spread of information throughout the system.

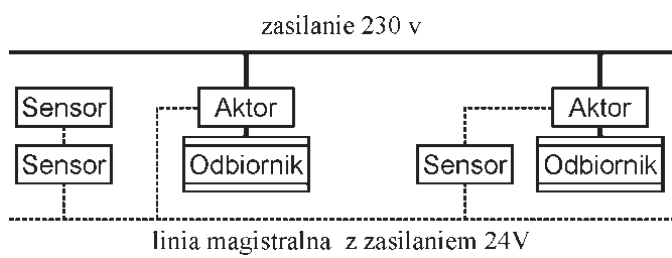

Fig. 2: The idea of the power circuit and control circuit in the installation of KNX/EIB

\section{The Concept of Intelligent Home}

Intelligent House should automatically adapt to the requirements of the operational performance environment or work with the program. The media, controlled by the system are governed without human intervention. It is, however, allow access to the functions of the home users and to provide for manual control. For example, the temperature is controlled automatically, but be able to make changes to the setpoint.

In addition, the room served by a system of KNX/ EIB device has to communicate with the user, that is, informing him of any changes in the house and gives possibility to change operating parameters. The installation of this system also has the ability to remotely monitor and change settings.

The project was executed in the system INSTABUS KNX / EIB, since it is the cheapest, and the installation will be routed over the suspended ceiling, the walls of the pipes will be carried out in the sewers.

Figure 3 shows the diagram of a smart lounge. Use a semicolon to indicate:

1.1.1-temperature controller with 8 buttons RCD 2022

1.1.2-radiator valve actuator 2176 SV

1.1.3-radiator valve actuator 2176 SV

1.1.4-binary output 2131.16 UP

1.1.5-schedule 8 button LS 2074 NABS

1.1.6-blind driver 2504 REG HE 
1.1.7-actor controlling luminaires 2092 X REG

1.1.8-light sensor 2092 LFX

1.1.9-binary input 2126 REG

1.1.10-fingerprint reader BIS 1950 NT

1.1.11-electromagnetic lock DAS 4370

1.1.12-motion sensor 360 PMU WW

1.1.13-automatic alarm communicator DAS 4610

1.1.14-of the light display of the siren DAS 4110

1.1.15-output binary REG 2304

1.1.16-LCD MT 701 with integrated four-button

1.1.17-output binary 2131.16 UP

1.1.18-driver blinds UP 2231

1.1.19-central unit 1000 REG IP IPZ

1.1.20-320 mA power supply system in 2005 REG

1.1.21-USB communication module USB 2130 REG

$\mathrm{R}$ - router; $\mathrm{P}$ - projector

PIR - Photoelectric sensor E3G

Glass - broken glass sensor WW SIF 4415

$\mathrm{M}$ - electric motors AC $230 \mathrm{~V}$

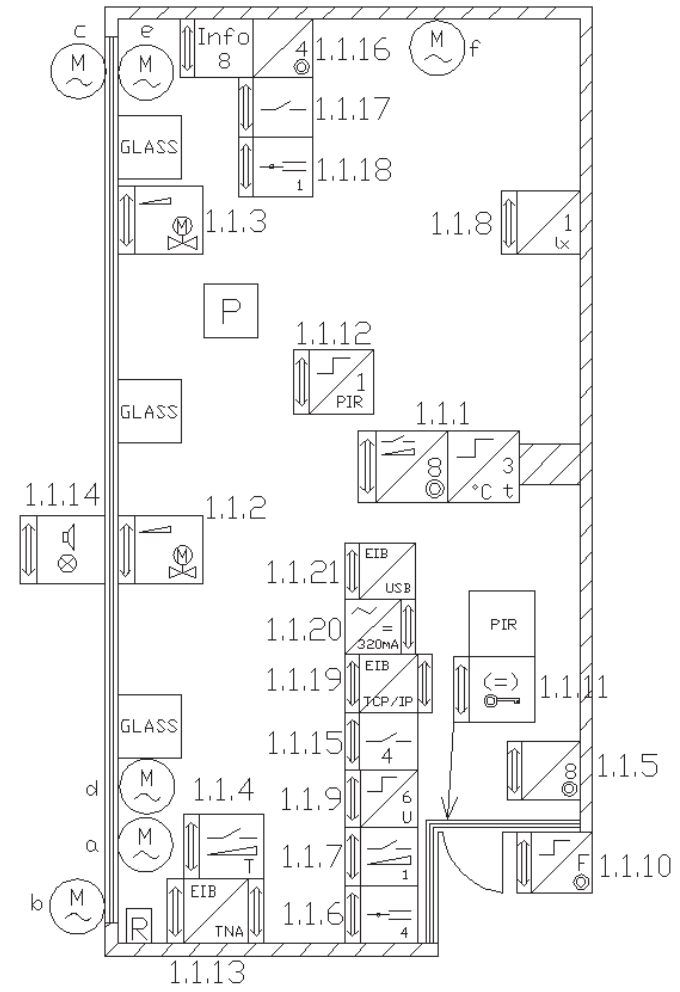

Fig. 3: Schematic layout of the smart laboratory room

\section{Programming System}

System operation requires programming individual devices and sensors. Used in this system, the program EIB Tool Software (ETS) enables the con- figuration of the system, forcing the control signals to visualize the current control system and operating parameters as well as direct and remote.

Process creation control program is intuitive. First you create a new project and select the medium of transmission of telegrams. You can choose from a main cable or voltage TP PL. Once approved, the window opens ADD Buildings, Topology, and Group Addresses (Fig. 4). In the Buildings must add a new building (Add Buildings), then add a new room (Add Rooms). At the end select the Add Devices to add specific devices. In the window, look for the device in the database (Fig. 5). At the beginning select the database producer, followed by product family, and at the end of the device type.

Clicking the right mouse button on the device (sensor), select Edit Parameters option to determine its function. Then repeat this step for other devices (sensors and actors). For equipment is automatically assigned a physical address. The final step is to assign address for block devices. For both components, sensor and actor, must be the same address such as $1 / 1 / 1$. To give the group address for the device, right-click on the item you want to program and select the option to link with.

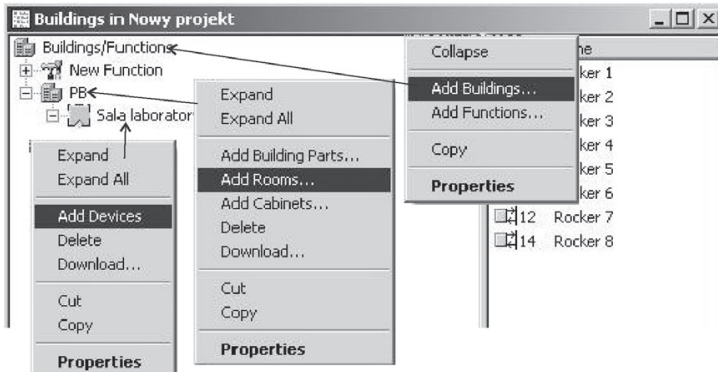

Fig. 4: Creating a New Project

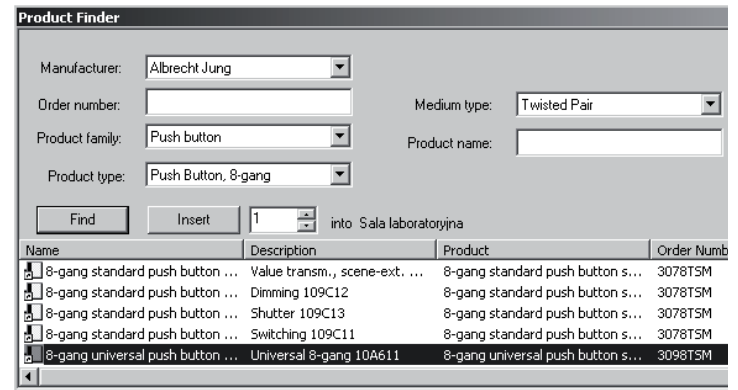

Fig. 5: Search Box Device

In cooperation with "Coral" which is located in Bialystok, built a position which allows you to: 
- know the functions of individual devices,

- programming equipment in accordance with the objectives and requirements of the user,

- testing of developed programs.

View the position shown in Figure 6 The power supply position to enter the security communications port, the module outputs the binary driver roller shutters, lighting control, potential-free input module, occupancy sensor, actuator heater and LCD display with 6 buttons.

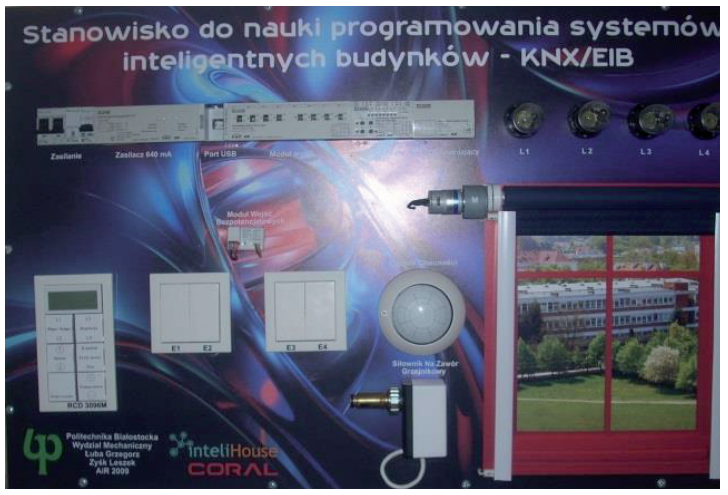

Fig. 6: Creating a New Project

\section{Conclusion}

System KNX / EIB is becoming more widely used to support banks, hospitals, representative rooms as well as from fellow users of houses and apartments.

Installed in the laboratory of the Department of Automation and Robotics will allow installation of an intelligent network topology to provide students and the idea of its operation. It will also enable learning of programming the system. Students in the classes will be involved in connecting devices on the network, configuration of devices and their programming. They will have the opportunity to prepare themselves in the building project an intelligent network. Programming Installation is simple and intuitive - a student who has met any programming language, program the device without any problem in ETS.

\section{References}

[1] Kamińska A., Radajewski R., Projektowanie instalacji elektrycznej w systemie EIB, Elektroinstalator, 6/2005, s. 28-34.

[2] Klajn A., Bielówka M., Instalacja elektryczna w systemie KNX/ EIB, Centralny Ośrodek Szkolenia i Wydawnictw SEP, Warszawa 2006

[3] Markiewicz H., Instalacje elektryczne, Wydawnictwo Nauko-
wo-Techniczne, Warszawa 2008.

[4] http://www.eib.pl/

[5] http://www.knx.org/pl/

[6] http://www.eib.lodman.pl/ 